\section{Accelerated Screening of Hazelnut Seedlings for Resistance to Eastern Filbert Blight}

\author{
Thomas J. Molnar, Sara N. Baxer, and Joseph C. Goffreda \\ Department of Plant Biology and Pathology, Foran Hall, 59 Dudley Road, \\ Cook College, Rutgers University, New Brunswick, NJ 08901-8520
}

Additional index words. Anisogramma anomala, Corylus avellana

\begin{abstract}
An eastern filbert blight resistance screening technique was developed that reduces the time required to identify susceptible Corylus avellana L. seedlings from the previously reported 14 to 16 months after inoculation to 6 to 7 months. To accomplish this, hazelnuts were harvested at maturity, treated with $\mathbf{G A}_{3}$, germinated, and grown for about 8 weeks at $24^{\circ} \mathrm{C}$ day $/ 18^{\circ} \mathrm{C}$ night with 16 -hour daylengths. Seedlings were then moved to a humidity chamber and inoculated with ascospores of Anisogramma anomala (Peck) E. Müller 3 times over 2 weeks by misting until run off with a solution of $1 \times 10^{6}$ ascospores $/ \mathrm{mL}$ in sterile distilled water. Following inoculation, seedlings were returned to the original greenhouse for 8 weeks and then were moved to a 10 to $15^{\circ} \mathrm{C}$ day $/ 5$ to $10^{\circ} \mathrm{C}$ night greenhouse with natural daylengths for 4 weeks. They were then moved to a $4^{\circ} \mathrm{C}$ cold room for 8 weeks to receive chilling. Afterwards, seedlings were returned to a greenhouse at $24^{\circ} \mathrm{C}$ day/18 ${ }^{\circ} \mathrm{C}$ night where stromata development was visible in 4 to 6 weeks.
\end{abstract}

The fungal disease eastern filbert blight (EFB), caused by Anisogramma anomala (Peck) E. Müller, is the primary limiting factor of European hazelnut (Corylus avellana L.) culture in the eastern U.S. (Fuller, 1908; Lagerstedt, 1975; Thompson et al., 1996). Finding sources of stable, high resistance to this pathogen is vital to developing improved cultivars that will thrive where the disease is present. Since the 1970s, much of the biology and epidemiology of EFB has been elucidated (Johnson and Pinkerton, 2002) and methods for the identification of resistant plants have been developed (Coyne et al., 1996, 1998, 2000; Lunde et al., 2000; Mehlenbacher and Thompson, 1991; Osterbauer, et al., 1997; Pinkerton et al., 1993). In spite of these advances, breeding for resistance remains time consuming and challenging due to $A$. anomala's long latent period that requires infected plants to cycle through a period of cold dormancy before development of characteristic stromata (Gottwald and Cameron, 1979, 1980; Stone et al., 1992). The standard greenhouse inoculation method (Standard Method) takes about 14 to 16 months from the time of inoculation before stromata formation is visible on susceptible genotypes (Johnson et al., 1994; Osterbauer et al., 1997). Given that it requires an additional 8 months to stratify the seed and produce a plant large enough to inoculate, it takes about 22 months from the time of nut harvest before the resulting seedlings can be identified as susceptible using the Standard Method (Osterbauer et al., 1997). Techniques such as microscope sectioning to look for the presence or absence of $A$. anomala hyphae and the use of an enzyme-linked immunosorbent assay (ELISA) can reduce the time period needed to identify susceptible genotypes, but they are an indirect measure

Received for publication 11 Mar. 2005. Accepted for publication 14 May 2005. of susceptibility and are technically demanding and labor intensive (Coyne et al., 1996, 1998; Lunde et al., 2000; Stone et al., 1992). The objective of this study was to efficiently stromata development in susceptible hazelnut seedlings as a means to quickly and directly identify resistant genotypes.

\section{Materials and Methods}

Plant material and culture. Nuts resulting from open pollination were collected from known EFB-susceptible hazelnut selections growing at the Rutgers Plant Science Research and Extension Station, Adelphia, N.J., in late August 2003. On the day of collection, kernels were removed from their shells with the aid of locking pliers and were soaked in $50 \mathrm{ppm} \mathrm{GA}_{3}$ (Sigma-Aldrich Co.) for about $12 \mathrm{~h}$. After soaking, kernels were germinated in flats $(43.2 \times$ $33.0 \times 6.4 \mathrm{~cm})$ containing a peat-based planting medium (Pro-mix BX, Premier Horticulture, Rivière-du-Loup, Québec). In about 3 to 4 weeks, seedlings were transplanted to $3.7-\mathrm{L}$ plastic containers using the same planting medium. Each plant was top-dressed with $5 \mathrm{~g}$ of 5- to 6-month release fertilizer (Osmocote Plus $15 \mathrm{~N}-9 \mathrm{P}_{2} \mathrm{O}_{5}-12 \mathrm{~K}_{2} \mathrm{O}$ with micronutrients, The Scotts Co., Marysville, Ohio) and watered as needed throughout the remainder of the experiment. The greenhouse was maintained at $24^{\circ} \mathrm{C}$ day $/ 18^{\circ} \mathrm{C}$ night with 16 -h daylengths. At about 8 weeks following germination (late October 2003), each tree (80 in total) was inoculated with ascospores of $A$. anomala 3 times over 2 weeks. Ten noninoculated control seedlings were included in this study. After inoculation, the seedlings were maintained in the greenhouse under optimal growing conditions with 16-h daylengths to continue active growth for an additional 8 weeks (until late December 2003). They were then moved to a reduce the time needed to induce $A$. anomala greenhouse maintained at 10 to $15^{\circ} \mathrm{C}$ day $/ 5$ to $10^{\circ} \mathrm{C}$ night with natural daylengths for 4 weeks to slow active growth. In early February 2004 they were moved to a $4{ }^{\circ} \mathrm{C}$ cold storage room in darkness for 8 weeks to receive about 1300 $\mathrm{h}$ of chilling [1300 $\mathrm{h}$ was within, or exceeded, the range of hours needed to fulfill the chilling requirements of vegetative buds of nearly all hazelnut cultivars examined by Mehlenbacher (1991)]. Seedlings were then returned to a warm greenhouse $\left(24^{\circ} \mathrm{C}\right.$ day $/ 18^{\circ} \mathrm{C}$ night with natural daylengths) on 1 Apr. 2004 to resume active growth and undergo weekly evaluations for stromata development. At the termination of this experiment (November 2004), disease incidence, length of the previous season's shoots, and EFB canker length were recorded for each plant and the proportion of last season's wood infected per plant was calculated. Symptomless plants were retained for further observations. They were moved in late November to a cool greenhouse (about 5 to $10{ }^{\circ} \mathrm{C}$ day $/ 0$ to $5{ }^{\circ} \mathrm{C}$ night with natural daylengths) to cycle through a period of dormancy. In March 2005 they were moved to a warm greenhouse $\left(24{ }^{\circ} \mathrm{C}\right.$ day/18 ${ }^{\circ} \mathrm{C}$ night with natural day lengths) to begin active growth.

Greenhouse inoculations. Branches containing mature $A$. anomala stromata were collected in January 2003 from infected hazelnut plants located at the Rutgers Horticultural Research Farm 2, North Brunswick, N.J., and stored at $-20{ }^{\circ} \mathrm{C}$ in polyethylene bags until needed. Ascospore suspensions were prepared similar to Johnson et al. (1994) by dissecting whole stromata from stem pieces, hydrating the stromata in sterile distilled water, then crushing the stromata with a mortar and pestle to liberate the asci and ascospores. The resulting liquid was filtered through a double layer of cheesecloth and diluted to about $1 \times$ $10^{6}$ ascospores $/ \mathrm{mL}$ in sterile distilled water with the aid of a bright-line hemocytometer (Hausser Scientific Co.). Seedlings were placed in a humidity chamber consisting of a polyvinyl chloride tube frame $(4.88 \times 1.83 \times 0.85 \mathrm{~m})$ set on top of a greenhouse bench and completely covered with 4-mil $(0.1-\mathrm{mm})$ polyethylene sheeting. Humidifiers (Trion Herrmidifier 707 Series, Herrmidifier Co., Sanford, N.C.) were placed at each end of the chamber and run as needed to maintain relative humidity near $100 \%$ for the entire 2-week period. On sunny days, shade cloth and the venting of small side-flaps were used to help keep the chamber close to ambient greenhouse temperatures $\left(24{ }^{\circ} \mathrm{C}\right.$ day $/ 18^{\circ} \mathrm{C}$ night). Ascospore suspensions were applied to seedlings by misting newly expanding shoot tips until runoff with a hand-held pump sprayer. Each seedling was inoculated three times starting on 28 Oct. 2003 with 72 $\mathrm{h}$ intervals between subsequent inoculations ( 31 Oct. and 3 Nov.). They remained in the humidity chamber for $7 \mathrm{~d}$ following the final inoculation. To reduce stress and keep plants actively growing, seedlings were acclimated back to the typical greenhouse environment by reducing humidity levels incrementally over 2 weeks following the inoculation period. This was accomplished by decreasing the run time of the humidifiers and by venting the chamber. 


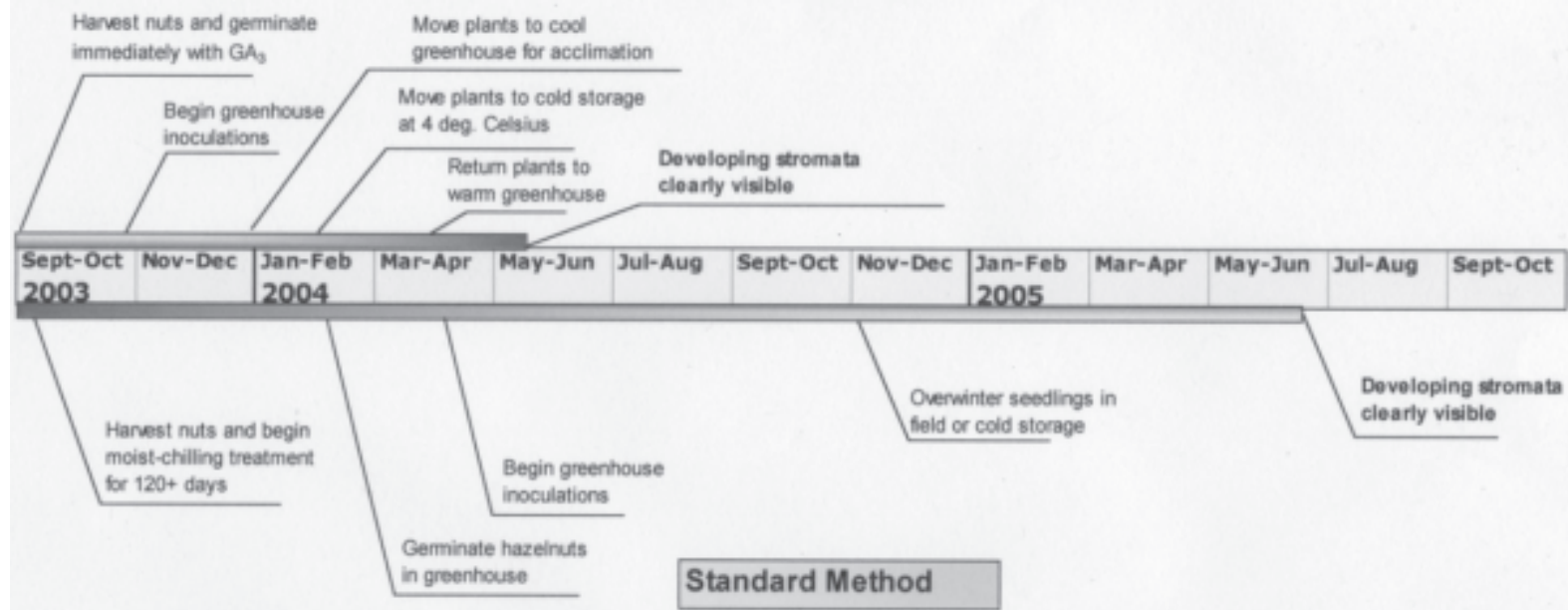

Fig. 1. Timeline showing steps of the Accelerated Method described in this study compared with the Standard Method.

\section{Results and Discussion}

Anisogramma anomala stromata development was visible the first week in May 2004, about 6 months after inoculation (Figs. 1 and 2). The experimental protocol (Accelerated Method) took about 9 months from harvest to visually identify EFB susceptible seedlings (Fig. 1). Of the 80 plants inoculated in this study, $65(81 \%)$ showed direct signs of
EFB, producing well-formed cankers bearing stromata (Fig. 2). Control plants showed no signs of EFB. Canker lengths of the infected plants ranged from 2.5 to $56.0 \mathrm{~cm}$ with a mean length of $20.3 \mathrm{~cm}$. Proportion of infected wood ranged from $4 \%$ to $46 \%$ with a mean of $19 \%$. The appearance of stromata was similar to those on naturally infected plants (Gottwald and Cameron, 1979), although development began earlier in the year (Fig. 2). Following the protocol of Stone et al. (1994), ascospores extracted from stromata in October 2004 germinated well and formed typical, slow-growing A. anomala colonies in vitro.

Results indicate the Accelerated Method can be useful for the rapid identification of hazelnut seedlings susceptible to EFB. With this technique, susceptible plants can be identified and discarded about 7 months after inoculation. The visibly healthy plants can be retained and field
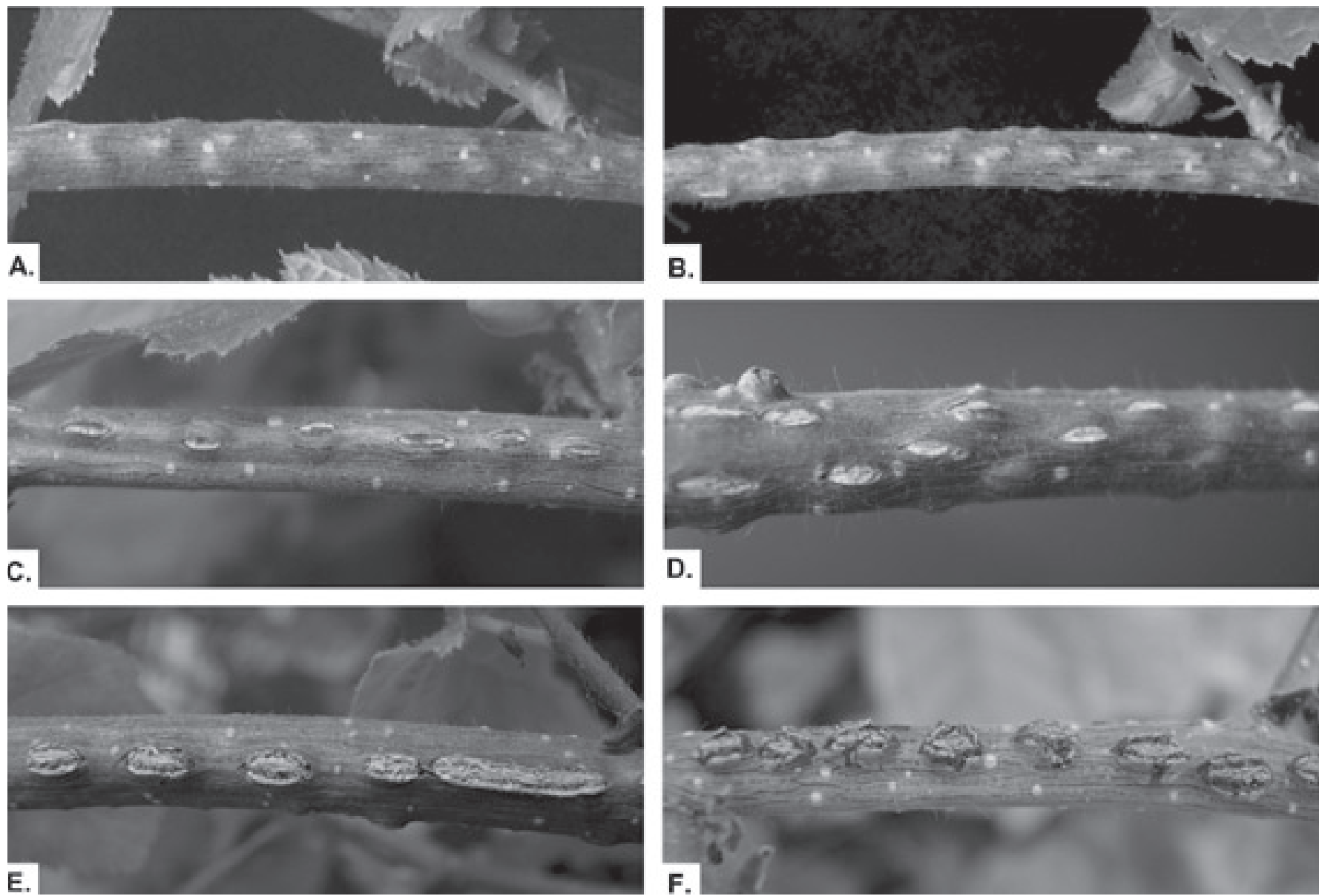

Fig. 2. Development of Anisogramma anomala stromata on stems of hazelnut seedlings inoculated in this study. Plants were removed from cold storage on 1 Apr. 2004. Series of development: (A) 5 May, (B) 12 May, (C) 27 May, (D) 4 June, (E) 10 July, and (F) 24 Sept. 
planted for further evaluations. This technique will allow breeders to screen seedling populations in one growing season, as opposed to the two growing seasons needed when using the Standard Method (Fig. 1). By using the accelerated method breeders can directly screen large populations segregating for single dominant resistance genes or newly collected germplasm for sources of high resistance without the use of indirect laboratory techniques such as ELISA or microscope sectioning or the added expense of field planting the entire population.

Inoculated seedlings showing no symptoms can be attributed to several possible factors: 1) the latency period of A. anomala; 2) plants possessing disease resistance genes; and 3) escape during inoculation.

Latency period of A. anomala. Several authors have reported that it occasionally takes $>24$ months after inoculation for some infected plants to express the characteristic stromata of $A$. anomala (Pinkerton et al., 1993; Stone et al., 1992). Of the 15 symptomless plants retained in this study for further observations, only 1 showed development of stromata on 25 Apr. 2005 similar to that in Fig. 2A. This indicates that the need for an extended latency period before development of stromata is not the major contributing factor to the presence of symptomless plants in this study.

Plants possessing disease resistance genes. Seedlings inoculated in this study were from open-pollination of EFB-susceptible plants. Plants containing the 'Gasaway' single gene for resistance (Mehlenbacher and Thompson, 1991) as well as other sources of resistance were in close proximity to the susceptible plants used as the source of nuts for this study. Thus, some seedlings may have genetic resistance to the fungus due to genes introduced from the pollen parents.
Escape during inoculation. Although care was taken to inoculate seedlings individually, no marking system was used as a backup to verify each seedling was sprayed. Therefore, it is possible due to human error that some plants were missed during inoculation. In addition, it has been reported that hazelnuts must be actively growing for infection of $A$. anomala to occur at a high frequency (Johnson et al., 1994; Stone et al., 1992), therefore escapes may also be due to some seedlings not being in the proper growth stage for infection at the time of inoculation. Recent personal experience of the authors has shown that by spraying both newly expanding shoot tips and the most recent 8 to $10 \mathrm{~cm}$ of growth and by using a marking system to verify inoculation of each plant, it is possible to reduce the number of escapes and achieve almost 100\% infection of susceptible genotypes.

\section{Literature Cited}

Coyne, C.J., S.A. Mehlenbacher, R.O. Hampton, J.N Pinkerton, and K.B. Johnson. 1996. Use of ELISA to rapidly screen hazelnut for resistance to eastern filbert blight. Plant Dis. 80:1327-1330.

Coyne, C.J., S.A. Mehlenbacher, and D.C. Smith. 1998. Sources of resistance to eastern filbert blight. J. Amer. Soc. Hort. Sci. 124:253-257.

Coyne, C.J., S.A. Mehlenbacher, K.B. Johnson, J.N Pinkerton, and D.C. Smith. 2000. Comparison of two methods to evaluate quantitative resistance to eastern filbert blight in European hazelnut. J. Amer. Soc. Hort. Sci. 125:603-608.

Fuller,A.S. 1908. The filbert or hazelnut, p. 118-146. In: The nut culturist. Orange Judd Company, New York.

Gottwald, T.R. and H.R. Cameron. 1979. Studies in the morphology and life history of Anisogramma anomala. Mycologia 71:1107-1126.

Gottwald, T.R. and H.R. Cameron. 1980. Infection site, infection period, and latent period of canker caused by Anisogramma anomala in European filbert. Phytopathology 70:1083-1087.

Johnson, K.B., J.N. Pinkerton, S.M. Gaudreault, and J.K. Stone. 1994. Infection of European hazelnut by Anisogramma anomala: Site of infection and effect on host developmental stage. Phytopathology $84: 1465-1470$.

Johnson, K.B. and J.N. Pinkerton. 2002. Eastern filbert blight, p. 44-46. In: B.L. Teviotdale, T.J. Michailides, and J.W. Pscheidt (eds.). Compendium of nut crop diseases in temperate zones. Amer. Phytopathol. Soc. Press, St. Paul, Minn.

Lagerstedt,H.B. 1975. Filberts, p. 456-488. In: J. Janick and J.N. Moore (eds.). Advances in fruit breeding. Purdue Univ. Press, West Lafayette, Ind.

Lunde, CF., S.A. Mehlenbacher, and D.C. Smith. 2000. Survey of hazelnut cultivars for response to eastern filbert blight inoculation. HortScience 35(4):729-731.

Mehlenbacher, S.A. 1991. Chilling requirements of hazelnut cultivars. Scientia Hort. 47:271-282.

Mehlenbacher, S.A. and M.M. Thompson. 1991 Occurrence and inheritance of resistance to eastern filbert blight in 'Gasaway' hazelnut. HortScience 26:410-411.

Osterbauer, N.K., K.B Johnson, S.A. Mehlenbacher, and T.L. Sawyer. 1997. Analysis of resistance to eastern filbert blight in Corylus avellana. Plant Dis. 81:388-394.

Pinkerton, J.N., K.B. Johnson, S.A. Mehlenbacher, and J.W. Pscheidt. 1993. Susceptibility of European hazelnut clones to eastern filbert blight. Plant Dis. 77:261-266.

Stone, J.K., K.B. Johnson, J.N. Pinkerton, and J.W. Pscheidt. 1992. Natural infection period and susceptibility of vegetative seedlings of European hazelnut to Anisogramma anomala. Plant Dis. 76:348-352.

Stone, J.K., J.N. Pinkerton, and K.B. Johnson. 1994. Axenic culture of Anisogramma anomala: Evidence for self-inhibition of ascospore germination and colony growth. Mycologia 86:674-683.

Thompson, M.M., H.B. Lagerstedt, and S.A. Mehlenbacher. 1996. Hazelnuts, p. 125-184. In: J. Janick and J.N. Moore (eds.). Fruit breeding. vol. 3. Nuts. Wiley, New York. 